\title{
SUPREME COURT OF THE UNITED KINGDOM: R v MOHAMMED GUL'
}

\author{
Lenara Ferreira Duarte Costa ${ }^{2}$
}

Sumário: 1 Descrição do fato. 2 Argumento da acusação. 3 Argumento da defesa. 4 Decisão do Supremo Tribunal do Reino Unido. 5 Considerações sobre a decisão.

Resumo: Trata-se de uma sentença proferida pelo Supremo Tribunal do Reino Unido em 23 de outubro de 2013 ao julgar o recurso do apelante Mohammed Gul contra decisão da Divisão Penal do Tribunal de Recurso da Inglaterra e do País de Gales proferida em 22 de fevereiro de 2012. Nesta apelação, o Tribunal de Recurso confrontou os argumentos da defesa com os preceitos consagrados perante o Direito Internacional e, mesmo com a identificação de leis internacionais humanitárias que pudessem excluir a culpabilidade do apelante, concluiu que os atos praticados pelo réu são facilmente subsumidos à definição de terrorismo da Seção 1 da Lei de Terrorismo de $2000^{3}$ da Inglaterra. Para tanto, o Tribunal de Recurso entendeu que ataques de um grupo armado não governamental contra as forças armadas de qualquer governo podem ser suscetíveis de incriminação pelas Leis de Terrorismo do Reino Unido, a despeito da regulação do Direito Internacional Humanitário. Assim, Mohammed Gul foi condenado em 5 anos de prisão por disseminar publicações terroristas, nos termos da seção 2 da Lei de Terrorismo de 20064. Ao analisar o recurso contra tal decisão, o Supremo Tribunal do Reino Unido considerou a definição de terrorismo imprudente e indesejável, mas, em seguida, utilizou-a como fundamento para confirmar a condenação do réu. Os argumentos que embasaram essa condenação serão expostos ao longo deste trabalho a partir da identificação dos argumentos da acusação e da defesa do réu.

\section{DESCRIÇÃO DO FATO}

O apelante nasceu na Líbia, em 24 de fevereiro de 1988, mas vivei grande parte de sua vida na Inglaterra e é um cidadão britânico estudante de Direito da Universidade de Londres. Em fevereiro de 2009, como resultado da execução de um mandado de busca e apreensão na casa de Mohammed, policiais encontraram em seu computador vídeos enviados a vários sites. Alguns desses vídeos apresentavam (i) ataques de membros da Al-Qaeda, do Talibã e de outros grupos ilegais contra alvos militares na Chechênia, nas forças da coalizão no Iraque e no Afeganistão, (ii) uso de dispositivos explosivos improvisados contra as for-

${ }^{1}$ DOI desta resenha: http://dx.doi.org/10.12957/cosmopolitan.2014.14944.

${ }^{2}$ Aluna da graduação em direito da Universidade do Estado do Rio de Janeiro.

3 A seção 1 da Lei de 2000 é intitulada "Terrorismo: Interpretação" e, conforme alteração feita pela Lei de 2.006 e pela Lei Antiterrorista de 2008, prevê o seguinte: "Terrorismo é definido como ação ou ameaça de ação com a finalidade de influenciar o governo ou uma organização internacional, de intimidar o público, ou que se destine a promover determinada política, causa religiosa, racial ou ideológica, caso envolva (a) violência grave contra uma pessoa, (b) grave dano à propriedade, (c) perigo de vida a uma pessoa, (d) criação de risco grave à saúde ou à segurança públicas, ou (e) intento de perturbar ou interferir sistema eletrônico gravemente." (Tradução nossa).

${ }^{4}$ Lei de Terrorismo de 2006, seção 2 Disseminação de Publicação Terrorista: "(1) Comete um crime aquele que pratica um ato que se enquadra na subseção (2) e, ao mesmo tempo: (a) pretende, como efeito de sua conduta, encorajar outros direta ou indiretamente a cometer, preparar ou instigar "atos de terrorismo"; (b) pretende, como efeito de sua conduta, dar assistência ao cometimento ou à preparação de tais atos; ou (c) é imprudente quanto ao saber se a sua conduta produz o efeito mencionado na alínea (a) ou (b)”. (Tradução nossa). 
ças de coalizão, (iii) trechos de "vídeos de martírio", e (iv) clipes de ataques contra civis, incluindo o ataque de 11 de setembro em Nova York. Nestes vídeos havia comentários que elogiavam a bravura e o martírio dos autores dos ataques, bem como incentivos para que outros fizessem o mesmo.

Os vídeos foram considerados publicações terroristas nos termos da seção 2 da Lei de Terrorismo de 2006 do Reino Unido. Desse modo, o apelante foi condenado em razão de apoiar o terrorismo por meio da disseminação de publicações terroristas. $O$ réu recorreu dessa decisão perante o Tribunal de Recurso da Inglaterra a partir do questionamento da abrangência da definição de terrorismo presente na lei inglesa. Para ele, a interpretação do artigo $1^{0}$ da Lei de 2000 e, em particular, o significado da palavra "terrorismo" devem ser discutidos, uma vez que, para concluir pela condenação, o júri deve ter acordado em que os vídeos encorajaram ou induziram as pessoas que os assistiram a cometer, preparar ou instigar "atos de terrorismo", assim como o apelante deve ter tido tal intenção ou ter agido com imprudência culpável.

Caso algumas ou todas as atividades mostradas nos vídeos enviados não tenham envolvido atos de terrorismo na acepção do artigo $1^{\circ}$ da Lei de 2000, é possível que o recorrente possa ser absolvido em alguns ou todos os cinco crimes em que foi condenado.

A seção 1 da Lei de 2000 identifica o terrorismo como constituído por três componentes. O primeiro é "ação ou ameaça de ação", dentro ou fora do Reino Unido, sendo que essa ação deve consistir, nomeadamente, em "violência grave", "sérios danos à propriedade", ou na criação de um risco grave para a segurança pública ou à saúde. O segundo componente é que a ação ou ameaça deve ser "destinada a influenciar o governo ou executada para intimidar o público". O terceiro componente exige que a ação ou a ameaça seja "empreendida com o propósito de fazer avançar uma causa política, religiosa, racial ou ideológica".

A definição de terrorismo na seção 1 na Lei 2000 é, em seu sentido natural, muito abrangente de fato. Por uma questão de linguagem comum, a definição parece cobrir qualquer tipo de violência ou dano à propriedade se for levada a cabo com o objetivo de influenciar o governo ou organização governamental internacional. Assim, abarca atividade militar ou quase militar destinada a derrubar um governo estrangeiro, mesmo que essa atividade seja aprovada (ofici- 
almente ou não) pelo governo do Reino Unido. A partir dessa conclusão, um insurgente 5 poderia ser considerado terrorista? Em consequência, o apoio a uma insurgência contra regime sem legitimidade popular poderia ser incriminado por uma lei doméstica antiterrorista? Esta é a questão mais polêmica da decisão, uma vez que a amplitude das Leis de Terrorismo do Reino Unido incriminaria tal conduta. É interessante observar que antes do presente caso ser apreciado pelo Tribunal de Recurso, o Tribunal da Coroa argumentou que insurgentes em conflitos armados de caráter não internacional não possuem status internacional legal nem imunidade de combate. Nesse diapasão, a responsabilidade criminal dos insurgentes seria matéria de lei doméstica6.

A fim de se entender o argumento utilizado pelo Supremo Tribunal do Reino Unido, faz-se necessário destacar os principais argumentos adotados pela acusação e pela defesa do réu.

\section{ARGUMENTO DA ACUSAÇÃo}

Para o Ministério Público, a conduta do réu constitui fato tipificado pelas Leis de Terrorismo da Inglaterra, logo, deve ser condenada. Admitiu-se a amplitude da definição de terrorismo, mas, por outro lado, tal abrangência é contrabalanceada pelo requerimento de que qualquer acusação de terrorismo deve ser autorizada pelo Diretor do Ministério, se a atividade ocorreu no Reino Unido, ou pelo Procurador Geral da República, se ela ocorreu no exterior. Garantir-seia, assim, que acusações criminais sejam formuladas apenas nos casos apropriados.

\section{ARGUMENTO DA DEFESA}

Para o réu, a definição de terrorismo dada pelo Direito Internacional é menos abrangente do que a definição dada pela legislação do Reino Unido. Como fundamento de tal assertiva, argumentou-se que é costume de Direito Internacional somente caracterizar atos criminosos praticados em tempo de paz como crimes de terrorismo e não durante conflitos armados. A exceção a tal assertiva são os atos de violência praticados na vigência de um conflito armado cujo

\footnotetext{
5 Insurgentes são grupos sublevados dentro de um Estado que visam a tomada do poder, cuja luta atinge certo grau de efetividade, sem, no entanto, constituir guerra civil. Os direitos e deveres dos insurgentes dependem do que lhes é atribuído pelos Estados que os reconhecem.

${ }^{6}$ Seção 29 da decisão do Tribunal de Recurso a respeito do caso Regina x Mohammed Gul.
} 
objetivo principal é disseminar o terror na população civil, o que configuraria, dessa forma, atos terroristas. Todavia, isso não foi o que ocorreu no presente caso. Em sua defesa, apelante disse que não concorda com os ataques feitos a civis expostos nos vídeos divulgados, mas acredita que o uso da força representa legítima defesa das pessoas que resistem à invasão de seu país. Dessa forma, o upload dos vídeos tinha por objetivo encorajar a resistência a ataques injustos ao invés de oferecer apoio a atos terroristas. Com base nesse argumento, o apelante foi absolvido pelo júri da acuação sobre o vídeo que continha cenas sobre o conflito israelense-palestino em Gaza, uma vez que Israel estava envolvido em uma incursão na Faixa de Gaza que envolveu ataques contra civis, escolas, hospitais e ambulâncias. Neste caso, o uso da força apenas constitui uma reação aos ataques de Israel, ou seja, um ato de legítima defesa contra uma agressão injusta.

Ademais, para a defesa, Mohammed Gul não poderia ser incriminado por ter carregado os vídeos supracitados na internet, visto que dentre as convenções internacionais sobre terrorismo que vinculam o Reino Unido há cláusula de exclusão para as ações levadas a cabo pelas partes em um conflito armado. Tratase de regulamentação do Direito Internacional Humanitário7 que deve ser respeitada pelo Reino Unido. Assim, o juiz teria errado por ter dito que os ataques contra as forças da coalizão no Iraque e no Afeganistão constituíam terrorismo na acepção da Lei de 2000. No entendimento da defesa, a definição de terrorismo presente nesta lei deve ser analisada em conjunto com os princípios de Direto Internacional, os quais não caracterizam como terrorismo ataques de insurgentes contra forças militares no curso de um conflito armado de caráter não internacional, nem os atos praticados no exterior que constituem hostilidade legal no âmbito do direito internacional humanitário, como atos de rebelião contra governos opressores.

Além disso, a defesa entende que os insurgentes no Iraque possuíam imunidade de combatente e beneficiavam-se do direito de participar das hostilidades sem sofrer nenhuma punição por isso, ou seja, possuíam imunidade em relação à lei penal nacional ${ }^{8}$. Em mesmo sentido, apresentou decisões em que o

\footnotetext{
7 Art. 19 da Convenção Internacional para a Repressão de Atentados Terroristas à Bomba combinado com o art. 21 da Convenção Internacional para a Supressão do Financiamento do Terrorismo.

$8 \mathrm{O}$ apelante se baseou no Protocolo I Adicional às Convenções de Genebra de 12 de Agosto de 
ataque de insurgentes contra as forças armadas não pode ser considerado como terrorismo 9 .

Quanto ao direito internacional, o recorrente tem dois argumentos a este respeito. O primeiro é que algumas disposições das Leis de 2000 e 2006 foram promulgadas para tornar efetivas as obrigações internacionais do Reino Unido. Portanto, a leitura de tais leis deve ser feita de forma sistemática e em concordância com que for sedimentado pelo Direito Internacional. O segundo argumento é que, como as Leis de 2000 e 2006 criminalizam certas ações "terroristas" cometidas fora do Reino Unido, o significado de "terrorismo" nessas leis não deve ser maior do que o que é aceito no Direito Internacional.

Em relação ao argumento de acusação no que tange à discricionariedade dada ao Ministério público para autorizar ou não o ajuizamento de ações, contra argumentou-se que o Ministério Público nunca teve por objetivo auxiliar na interpretação da legislação que envolva a criação de uma ou várias infrações penais. Isso equivaleria a dizer que o Legislativo, cujo dever primário é fazer a lei publicamente, estaria delegando a decisão de criminalizar determinada atividade para efeitos de procedimento penal a alguém nomeado pelo Executivo. Dessa forma, o Parlamento abdicaria de parte significativa da sua função legislativa em favor do Ministério Público e do Procurador-Geral que, embora sejam responsáveis perante o Parlamento, não foram eleitos e não agem aberta e democraticamente como o Parlamento.

\section{DECISÃO DO SUPREMO TRIBUNAL DO REINO UNIDO}

A decisão do Tribunal concentra-se na análise da aplicação da definição de terrorismo a casos ocorridos durante conflitos armados, bem como na relação entre a lei doméstica e lei internacional ao criminalizar condutas.

O Supremo Tribunal do Reino Unido entendeu que a definição de terrorismo adotada pela Lei de Terrorismo de 2001 é imprudente e indesejável, mas

\footnotetext{
1949 relativo à Proteção das Vítimas dos Conflitos Armados Internacionais, o qual dispõe que "conflitos armados em que os povos lutam contra a dominação colonial e a ocupação estrangeira e contra os regimes racistas no exercício do direito dos povos à autodeterminação, consagrado na Carta das Nações Unidas e na Declaração Relativa aos Princípios do Direito Internacional Respeitante às Relações Amigáveis e à Cooperação entre os Estados nos termos da Carta das

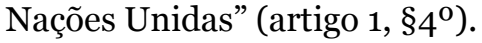

9 Tal entendimento foi adotado nos casos KJ (Sri Lanka) $v$ Secretary of State for the Home Department [2009] EWCA Civ 292 e Secretary of State for the Home Department $v$ DD (Afghanistan) [2010] EWCA Civ 1407.
} 
a utilizou para incriminar a conduta do réu sob o argumento de que, diante da inexistência de consenso internacional a respeito da definição de terrorismo, a lei nacional deve ser aplicada.

Além disso, o Tribunal salientou que também não há acordo a respeito de quando um ataque dos chamados "freedom fighters" pode ser isentado de incriminação.

Ademais, o Tribunal de Recurso decidiu que não há nenhuma razão para o Parlamento não poder criminalizar atos de "terrorismo", como definido na seção 1 da Lei de 2000, uma vez que "regras de direito obrigatórias para Estados emanam de sua própria vontade" e que "os Estados têm o direito de fazer o que não é proibido pelo Direito Internacional" ${ }^{10}$. Desse modo, não haveria nenhuma razão para ler restritivamente a ampla definição de terrorismo. Entendeu-se, ademais, que é desnecessário examinar se existe ou não uma definição acordada internacionalmente de "terrorismo", visto que o presente caso envolve um cidadão do Reino Unido cujos atos foram cometidos no Reino Unido.

Argumentou-se, também, que a amplitude da definição foi deliberadamente adotada. Antes da Lei de 2000 ser aprovada, parlamentares realizaram inúmeros debates acerca do que deveria ser considerado terrorismo. Ao fim, concluíram que o "terrorismo" não pode ser definido de modo estrito, tendo em vista as diversas formas que tal prática pode tomar, bem como as mudanças inevitáveis que ocorrerão nas relações internacionais, nos regimes políticos de outros países e na política externa do Reino Unido.

Diante do exposto, a amplitude da definição de terrorismo foi reconhecida pela Corte, mas esta se considerou incompetente para restringir a abrangência dada pelo legislador, mesmo que representasse possibilidade de invasões sérias na liberdade pessoal, visto que a amplitude da definição foi considerada durante os debates do parlamento acerca da Lei de 2000 e de suas posteriores emendas.

\section{CONSIDERAÇÕES SOBRE A DECISÃO}

A Lei de Terrorismo de 2006 do Reino Unido emendou a Lei 2000 para incluir novas ofensas, dentre elas o "encorajamento de terrorismo e disseminação de publicações terroristas” (seção 1 e 2 da lei). Trata-se de uma evidente al-

${ }^{10}$ Seção 57 da decisão do Tribunal de Recurso a respeito do caso Regina x Mohammed Gul. 
teração na orientação político criminal. Desse modo, pode-se observar que a política criminal do Reino Unido optou por minimizar garantias a pretexto de maximizar o controle da criminalidade.

A decisão do Supremo Tribunal do Reino Unido segue esta mesma orientação. Assim, ela aplica uma lei que vai de encontro a garantias sedimentadas pelo Direito Internacional Humanitário, além de conferir poder discricionário ao Ministério Público para este autorizar ou não a repressão a uma conduta que nem sequer é claramente abarcada pelo tipo penal. O âmbito de incidência da Lei 2000 de Terrorismo é tão amplo que acabou por incriminar atos de mero apoio à luta contra repressão de um governo. 